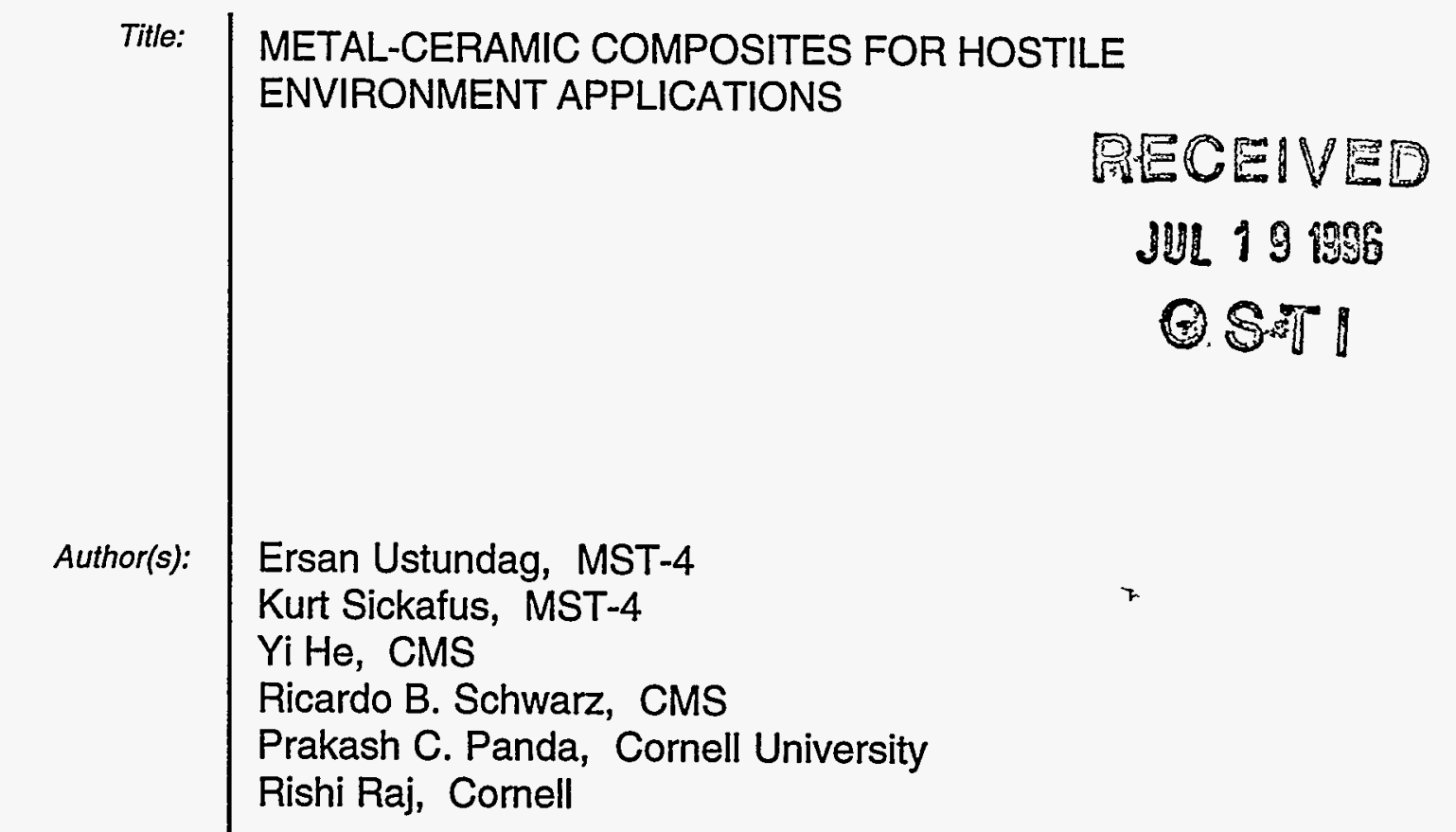

Submitted to: Advanced in Ceramic Matrix Composites III, N.P. Bansal (ed.), Ceramic Transactions, vol. 74, American Ceramic Society, Westerville, OH (1996).

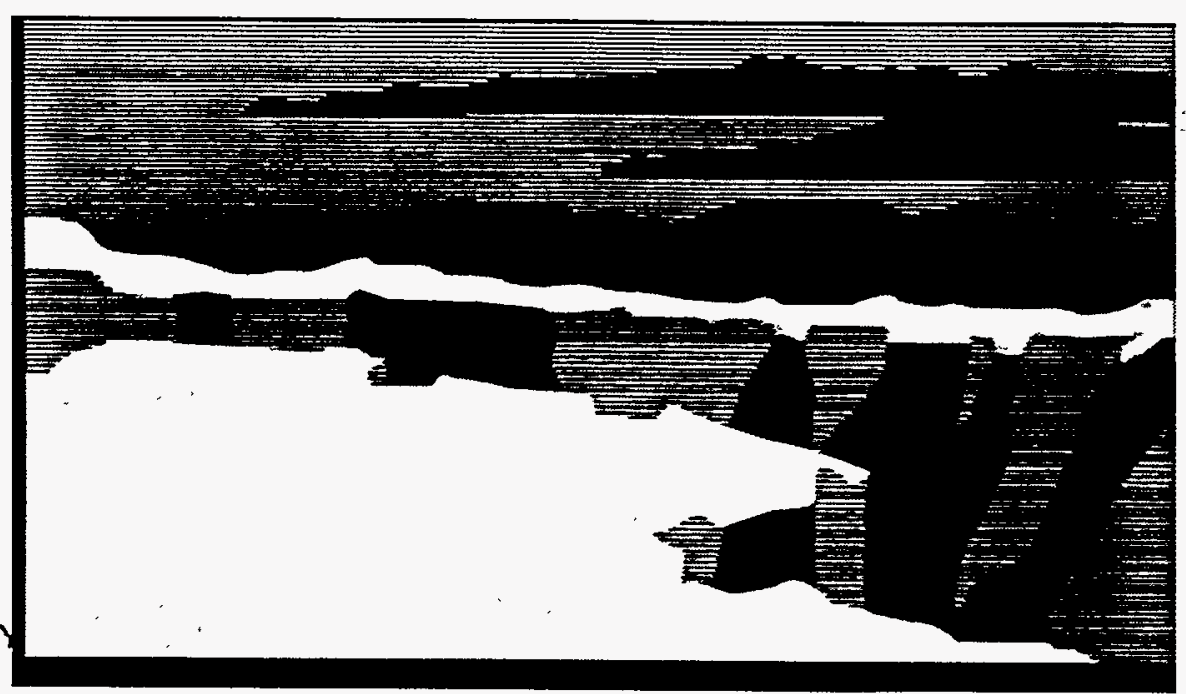

Los Alamos Natlonal Laboratory, an affirmative actionequal opportunity employer, is operated by the University of Califomia for the U.S. Department of Energy under contract W-7405-ENG-36. By acceptance of this article, the publisher recognizes that the U.S. Govemment retains a nonexclusive, royalty-free license to publlsh or reproduce the published form of this contribution, or to allow others to do so, for U.S. Govemment purposes. The Los Alamos National Laboratory requests that the publisher identify this article as work performed under the auspices of the U.S. Department of Energy. 


\section{DISCLAIMER}

Portions of this document may be illegible in electronic image products. Images are produced from the best available original document. 


\section{LA-UR - 94-XX-XXX}

Title: Metal-Ceramic Composites for Hostile Environment

\section{Applications}

Author(s): $\quad$ Ersan Üstündag, Kurt E. Sickafus, Yi He and Ricardo B. Schwarz, Materials Science and Technology Division, Los Alamos National Laboratory, Los Alamos, NM 87545

Prakash C. Panda and Rishi Raj, Department of Materials Science and Engineering, Cornell University, Ithaca, NY 14853

To be published in: Advances in Ceramic Matrix Composites III, N. P. Bansal (ed.), Ceramic Transactions, vol. 74, American Ceramic Society, Westerville, OH (1996)

By acceptance of this article, the publisher recognizes that the U.S. government retains a nonexclusive, royalty-free license to publish or reproduce the published form of this contribution, or to allow others to do so, for U.S. Government purposes.

The Los Alamos National Laboratory requests that the publisher identify this article as work performed under the auspices of the U.S. Department of Energ:.

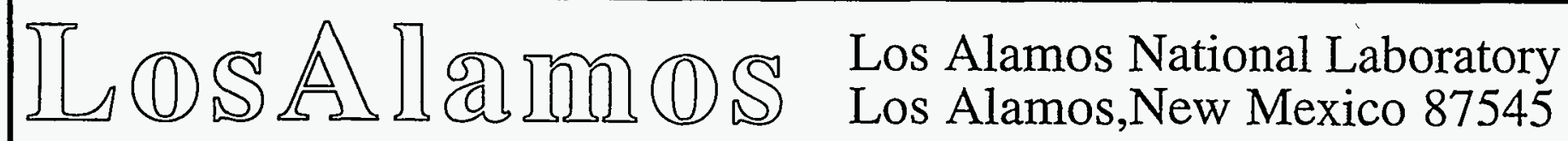




\title{
METAL-CERAMIC COMPOSITES FOR HOSTILE ENVIRONMENT APPLICATIONS
}

Ersan Üstündag, Kurt E. Sickafus, Yi He, Ricardo B. Schwarz, Materials Science and Technology Division, Los Alamos National Laboratory, Los Alamos, NM 87545

Prakash C. Panda and Rishi Raj, Department of Materials Science and Engineering, Cornell University, Ithaca, NY 14853

\begin{abstract}
We have developed a new metal-ceramic composite made from vanadium metal (V) and a non-stoichiometric magnesio-aluminate spinel ceramic. Three vanadium-spinel compositions, 40-60, 50-50, and 60-40 (by volume) were prepared by hot pressing mixtures of commercial powders. The properties of these composites were determined by measuring coefficient of thermal expansion, hardness, elastic constants, and fracture toughness. Radiation damage studies were performed on 50-50 vanadiumspinel composite samples using $1.5 \mathrm{MeV} \mathrm{Xe}{ }^{+}$ions, with samples held both at $20 \mathrm{~K}$ and at room temperature. Room temperature irradiated samples exhibited very little change in microstructure, indicating that this composite has radiation damage resistance qualities such as resistance to volume swelling under particle bombardment. This feature, as well as other properties reviewed in this paper, suggest that vanadiumspinel composites are attractive structural materials for fusion reactor design.
\end{abstract}

\section{INTRODUCTION}

We report here on the development of a metal-ceramic composite for structural design applications in hostile environments (neutron, energetic particles, etc.). The constituents of the composite are vanadium (V) metal and magnesio-aluminate spinel ceramic $^{\dagger}$. A potential application for this composite is as a first-wall material in a deuterium-tritium magnetic fusion reactor (MFR). Three classes of materials are currently being considered for this application: (1) austenitic [1] and ferritic/martensitic steels [2]; (2) vanadium-base alloys [3]; and (3) silicon-carbide/silicon-carbide (SiC-SiC)

\footnotetext{
- Also with Jupiter Technologies, Cornell Industrial Research Park, Ithaca, NY 14850. ${ }^{\dagger}$ The spinel used in this study was non-stoichiometric with a nominal composition of $\mathrm{MgO} \cdot \mathrm{xAl}_{2} \mathrm{O}_{3}(\mathrm{x} \sim 1.3)$. Alumina has a wide solid solubility in magnesio-aluminate spinel. The single phase spinel can form in the entire range of $x=1$ to 5 . This single phase solid solution is retained in metastable form when the material is cooled from the fabrication temperature.
} 
composites [4]. We expect vanadium-spinel composites to exhibit a number of attractive properties which may make them competitive with the materials described above:

- Good radiation resistance (e.g., absence of volume swelling during particle irradiation). Evidence for the radiation resistance of vanadium-spinel composites is presented in this paper.

- High melting point composite. The melting points of the constituents are $T_{m}(V)=$ $2180 \mathrm{~K}$ [5] and $\mathrm{T}_{\mathrm{m}}\left(\mathrm{MgO} \cdot \mathrm{xAl}_{2} \mathrm{O}_{3}\right)=2200$ to $2400 \mathrm{~K}$ [6]. Therefore, the high temperature mechanical properties (especially creep resistance) of this composite are predicted to be very good. The creep resistance of this material is expected to be superior to that of vanadium-base alloys due to the presence of the ceramic phase.

- Good thermal shock/fatigue resistance. The thermal expansion properties of vanadium and spinel are well-matched. The mean coefficient of linear thermal expansion for vanadium (temperature range $300-1200 \mathrm{~K}$ ) is $\alpha=10.53 \cdot 10^{-6} \mathrm{~K}^{-1}$ [7], while for $\mathrm{MgO} \cdot \mathrm{XAl}_{2} \mathrm{O}_{3}$ (temperature range $300-1200 \mathrm{~K}$ ) ${ }^{\circ} \alpha=8.7 \cdot 10^{-6} \mathrm{~K}^{-1}$ [8].

- Good thermal conductivity, especially if the composite exhibits a contiguous metal phase. Selected thermal conductivity values in the vicinity of the design temperature $\left(\sim 750^{\circ} \mathrm{C}\right.$ for first-wall vanadium-base alloys [9]) are as follows: for vanadium, $k$ $\left(\mathrm{T}=700^{\circ} \mathrm{C}\right)=38.6 \mathrm{~W} / \mathrm{m}-\mathrm{K}[10]$; for spinel, $k\left(\mathrm{~T}=1000^{\circ} \mathrm{C}\right)=5.86 \mathrm{~W} / \mathrm{m}-\mathrm{K}[11]$.

- High toughness and strength. We anticipate that vanadium-spinel composites will exhibit high fracture toughness and possess high-strength metal-ceramic interfaces. Our experience indicates that spinel bonds readily to metals, hence the latter property. As we will show later, the mechanical properties can be further optimized once we produce fine-grained composite microstructures and control the amount of impurities present in vanadium.

This paper presents the results of preliminary irradiation and characterization experiments on vanadium-spinel composites and examines the merits of these new materials for fusion reactor applications.

\section{EXPERIMENTAL PROCEDURE}

Vanadium powders were obtained from Goodfellow Corporation ${ }^{\dagger}$ with $99.7^{+} \%$ purity. The maximum particle size of the vanadium powder was $45 \mu \mathrm{m}$, while the average particle size was in the range $5-15 \mu \mathrm{m}$. A chemical analysis of the vanadium powder revealed the following impurities (in ppm by weight): Al 100; $\mathrm{Ca}<100 ; \mathrm{Fe} \mathrm{100;} \mathrm{Mg}$ $<100$; Zr 100. Magnesio-aluminate spinel powder was obtained from Alcoa*, with composition $\mathrm{MgO} \times \mathrm{Al}_{2} \mathrm{O}_{3}(\mathrm{x} \sim 1.3)$, and with $99.99^{+} \%$ purity. The average spinel particle size was about $10 \mu \mathrm{m}$. Typical impurities in chemical assays of the spinel powder include $\mathrm{CaO}\left(<0.3\right.$ wt. \%), $\mathrm{Fe}_{2} \mathrm{O}_{3}\left(<0.1\right.$ wt. \%), $\mathrm{SiO}_{2}\left(<0.06\right.$ wt. \%), and $\mathrm{Na}_{2} \mathrm{O}$ $(<0.15 \mathrm{wt} . \%)$. Vanadium and spinel powders were mixed in volume proportions of $40-60,50-50$, and $60-40$, wetted with a few cc of isopropanol, and milled with zirconia balls using a vibratory mill for two hours. Henceforth, these sample composi-

\footnotetext{
- Thermal expansion of spinel is not seen to be a strong function of its stoichiometry in the range of $x$ present in our material [8].

+ Goodfellow Corporation, 800 Lancaster Ave., Berwyn, PA 19312-1780

* Alcoa Industrial Chemicals Division, P.O. Box 300, Bauxite, AR 72011
} 
tions will be denoted 40-60 vanadium-spinel, etc. The powders were then loaded into graphite dies lined with grafoil and hot-pressed in an argon atmosphere using a load of $14-21 \mathrm{MPa}$ in the temperature range $900-1550^{\circ} \mathrm{C}\left(900^{\circ} \mathrm{C}\right.$ was the initial temperature and $1550^{\circ} \mathrm{C}$ the final temperature during hot pressing). The hot-pressing temperature was maintained in the range $1500-1550^{\circ} \mathrm{C}$ for one hour. The grafoils used for hot pressing were lined with boron nitride. The surfaces of the pellets produced by hot pressing were ground to remove any graphite and carbide layers formed during heating. Pellet densities were then measured using the Archimedes' Method (see, e.g., [12]) and the results are shown in Table I.

Table I. Vanadium-Spinel Sample Compositions and Particle Sizes Before Hot Pressing, and Sample Densities Following Hot Pressing

\begin{tabular}{|c|c|c|c|c|c|c|}
\hline $\begin{array}{c}\text { Sample } \\
\text { ID } \\
\end{array}$ & \multicolumn{2}{|c|}{$\begin{array}{c}\text { Composition } \\
\text { (Vol. \%) }\end{array}$} & \multicolumn{2}{|c|}{$\begin{array}{l}\text { Initial Particle Size } \\
(\mu \mathrm{m}) \\
\end{array}$} & $\begin{array}{l}\text { Density } \\
\left(\mathrm{g} / \mathrm{cm}^{3}\right) \\
\end{array}$ & $\begin{array}{c}\text { Theoretical } \\
\text { Density }^{\dagger}\left(\mathrm{g} / \mathrm{cm}^{3}\right)\end{array}$ \\
\hline & $\mathrm{V}$ & Spinel & V & Spinel & & \\
\hline VS-1 & 50 & 50 & $10-20$ & 5 & 4.89 & 4.85 \\
\hline VS-3 & 40 & 60 & $20-45$ & 10 & 4.66 & 4.59 \\
\hline VS-4 & 50 & 50 & $20-45$ & 10 & 4.91 & 4.85 \\
\hline VS-5 & 60 & 40 & $20-45$ & 10 & 5.20 & 5.10 \\
\hline
\end{tabular}

The coefficient of linear thermal expansion (CTE) of one of the 50-50 composites (VS-1) was determined employing a Perkin-Elmer dynamic mechanical analyzer (DMA-7) operated in the expansion mode. A parallelepiped-shaped specimen of about $1.2 \times 1.2 \times 7.5 \mathrm{~mm}$ dimensions was used and two heating/cooling cycles were completed with a maximum temperature of $475^{\circ} \mathrm{C}$ in air.

The elastic constants of the same material were measured by a resonant ultrasound spectroscopy (RUS) technique. The RUS technique is a non-destructive technique based on ultrasonic excitation and measurement of the mechanical resonant frequencies of a small sample having a regular shape [13]. The material was assumed to be isotropic, with two independent second-order elastic stiffness constants: $C_{11}$ and $C_{44}$. The specimen used in our RUS measurements had dimensions of $1.276 \times 1.330 \times 2.356$ mm. The elastic constants of the other three composites were measured using the pulse-echo ultrasonic technique (see, for example, [14]).

Hardness testing was performed on a Nikon QM-2 High Temperature Microhardness Tester under a vacuum of about $10^{-4} \mathrm{~Pa}$. A sapphire Vickers indenter tip was used at loads varying between 200 and $1000 \mathrm{~g}$. The measurements were done from room temperature to $800^{\circ} \mathrm{C}$. This temperature was chosen to avoid oxidation in vanadium. Five indents were made at each temperature. In addition to the VS-1 composite, we

\footnotetext{
- Grafoil ${ }^{\text {nt }}$, UCAR Carbon Co. Inc., P.O. Box 94637, Cleveland, OH 44101.

† Obtained using a 'rule of mixtures.' If a rule of mixtures is applicable, this implies that there is no reaction product between the vanadium and spinel. The vanadium content appears to be about 3 vol. \% more than the compositions specified in Table I.
} 
also tested a commercially-pure vanadium sample and a hot-pressed spinel specimen with similar stoichiometry as that in our samples.

The fracture toughness of the other three composites were determined using the Chevron notch technique [15] in three-point bending. A screw-driven testing machine (Instron 1125) operated under constant cross-head speed was used to apply load on a bending fixture with $8 \mathrm{~mm}$ span. Cross-head speeds varied between 0.005 $\mathrm{mm} / \mathrm{min}$ and $0.025 \mathrm{~mm} / \mathrm{min}$ for different tests, but no effect of cross-head speed was observed on fracture toughness. Four bars from each composite with dimensions of $2.25 \times 2.25 \times 11.6 \mathrm{~mm}$ were tested. The Chevron notch was $\sim 0.15 \mathrm{~mm}$ wide and its tip was $\sim 0.68 \mathrm{~mm}$ away from the lower edge of the specimen yielding an $\alpha_{0}$ of $\sim 0.3$ and an $\alpha_{1}$ of $\sim 1.0$ [15]. The fracture toughness was calculated using the "peak-loadtechnique" which employed the analytical expression developed by Wu ([16], see also [17]). A commercial polycrystalline alumina with known properties was also tested to check the setup. The fracture toughness of the alumina was $4.55 \mathrm{MPa} \cdot \mathrm{m}^{1 / 2}$, close to the literature value of $4.50 \mathrm{MPa} \cdot \mathrm{m}^{1 / 2}$ [17].

Transmission electron microscopy (TEM) samples were produced by mechanical and ion thinning. These samples were then examined using a Vacuum Generators HB601UX STEM (scanning TEM) operating at $100 \mathrm{kV}$. Chemical analyses of the samples were performed on the STEM using an Oxford Instruments-Link energydispersive $X$-ray spectrometer (EDXS). Additional microstructural characterization was performed on a CamScan scanning electron microscope (SEM) at $20 \mathrm{kV}$.

Selected 50-50 vanadium-spinel TEM samples (VS-1) were irradiated with $1.5 \mathrm{MeV}$ $\mathrm{Xe}^{+}$ions at a dose rate of $4.3 \cdot 10^{11} \mathrm{Xe} \mathrm{cm}^{-2} \mathrm{~s}^{-1}$ using the HVEM-Tandem Facility at Argonne National Laboratory [18]. The maximum dose obtained in this experiment

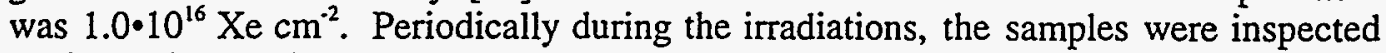
in-situ, using both TEM bright-field and selected-area electron diffraction modes, with the electron microscope operating at $400 \mathrm{kV}$. Two irradiation experiments were carried out: one irradiation at room temperature, nominally $\sim 300 \mathrm{~K}$, and a second irradiation at $20 \mathrm{~K}$. The details of this experiment are described in a separate publication [19]. Simulations using the Monte Carlo ion transport code TRIM [20] indicate that at a depth of $50 \mathrm{~nm}$ in spinel, the component of damage due to atomic displacements is about 1 displacement per atom (dpa) per $10^{15} \mathrm{Xe}$ ions $\mathrm{cm}^{-2}$ in spinel and 1.7 dpa for vanadium.

\section{RESULTS}

\section{Microstructures and Effect of Irradiation}

Fig. 1 is an SEM image of the cross section of composite VS-1. The vanadium particles have a bimodal size distribution, where large particles $(\sim 10-50 \mu \mathrm{m}$ diameter) are seen together with much smaller ones $(<5 \mu \mathrm{m}$ diameter). In all the composites studied, the volume fraction of vanadium was well above the percolation limit $(\sim 17$ vol.\%) as confirmed by electrical conductivity measurements. A high magnification view of the same sample is shown in Fig. 2 where small vanadium particles and a large number of twins are observed inside the vanadium grains. The origin of these twins is un-

\footnotetext{
- AD998E grade, $99.8 \%$ pure, from Coors Ceramics Co., Golden, CO.
} 


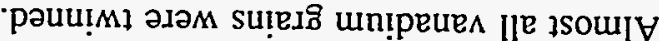

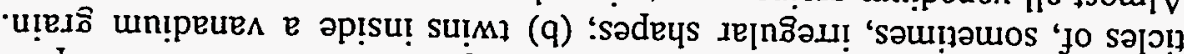

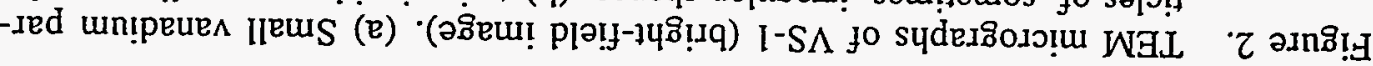

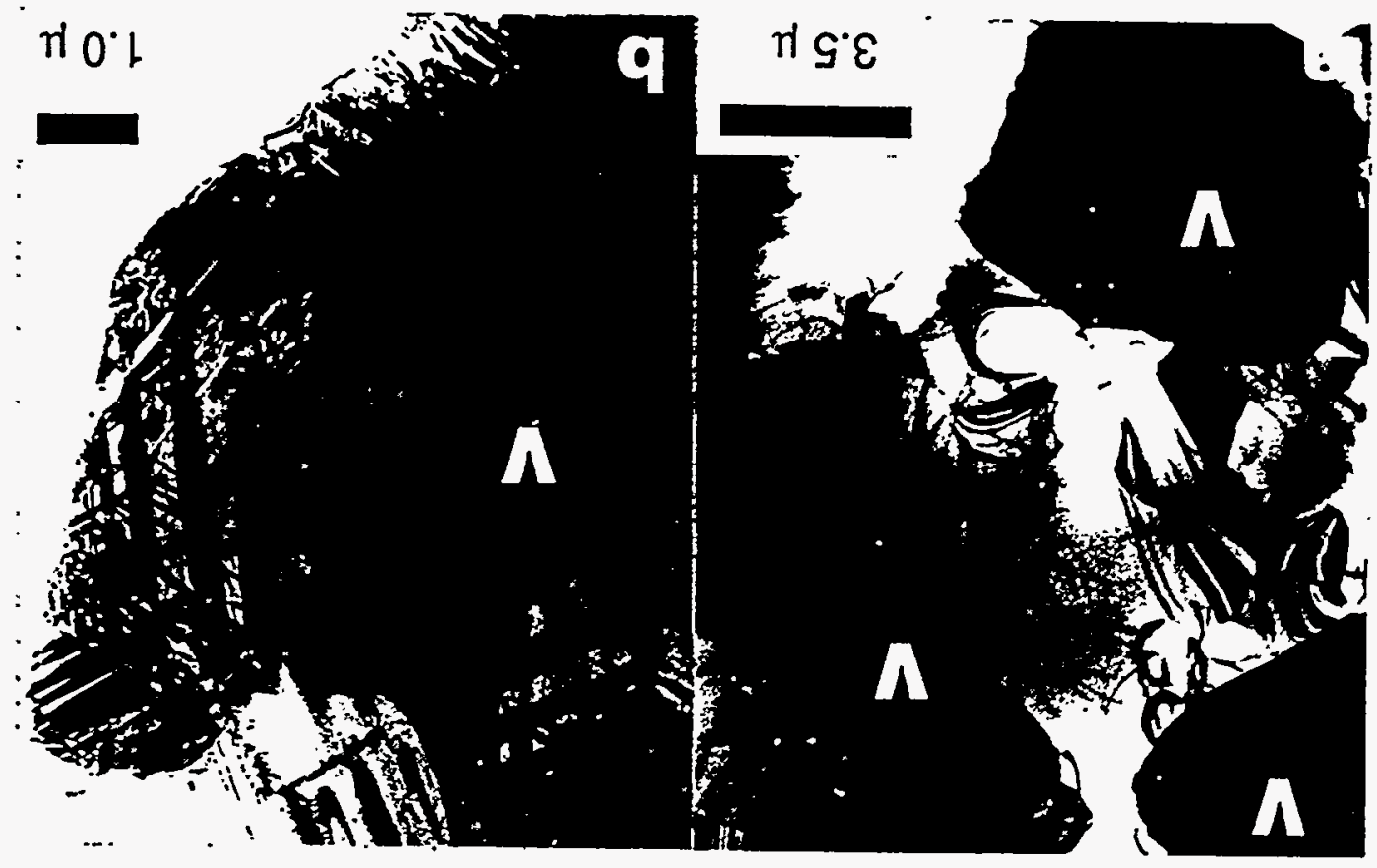

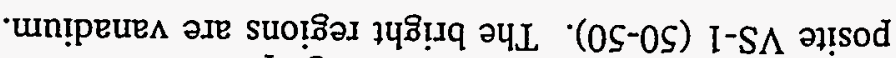

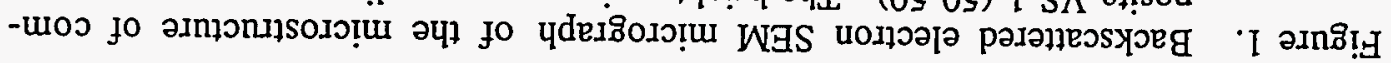

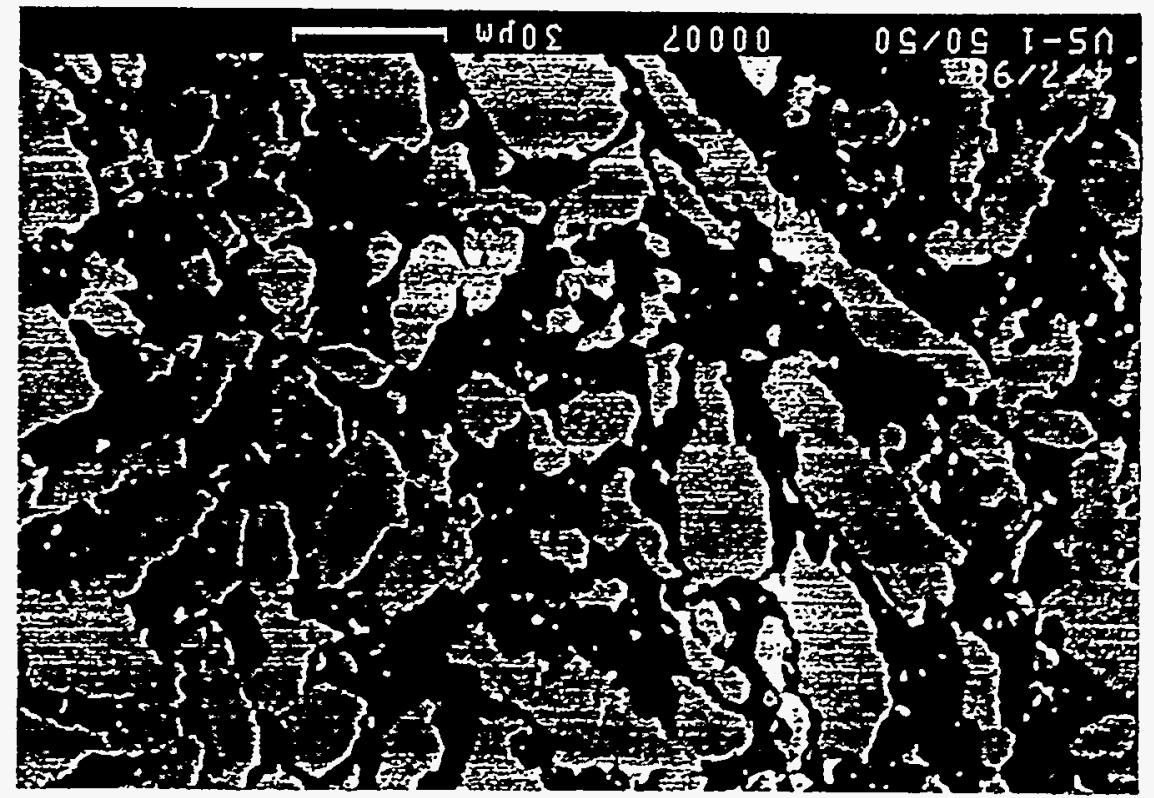


known at present, but they could form during cooling from the hot pressing temperature due to the CTE mismatch between vanadium and the spinel matrix. Their presence, however, indicates the possibility of brittle behavior in vanadium which will occur if the ductile-to-brittle-transition temperature (DBTT) of the metal has been increased to the room temperature level from its normal value of about $-150^{\circ} \mathrm{C}$ to $-200^{\circ} \mathrm{C}$ [21]. This point will be further discussed in the next section.

The TEM investigations show that there are no reaction products at the interfaces between vanadium and spinel particles (see [19] about details). Some pores were evident at grain boundaries in the spinel phase and in addition, pockets of an amorphous or glassy phase (up to $1 \mu \mathrm{m}$ in size) were found scattered throughout the microstructure. The glassy-phase pockets were rich in some of the impurities found in the initial powders, such as $\mathrm{Fe}, \mathrm{Ca}$, and $\mathrm{Si}$. Phosphorus $(\mathrm{P})$ was also found in the glassy pockets. However, it was not present in the particle assays.

EDXS analyses on the same specimen indicate that significant quantities (several at.\%) of at least two impurities, $\mathrm{P}$ and $\mathrm{Ca}$, are segregated at spinel grain boundaries [19]. It is likely that the segregation of these species to grain boundaries is linked to the formation of the glassy-phase pockets. These impurities possess limited solubility in both vanadium and spinel; hence, they are exsolved and accumulate at grain boundaries and triple junctions. There was also some vanadium dissolved in spinel grains (on the order of several at.\%).

To assess the radiation damage resistance of these composites, a TEM sample of composite VS-1 was irradiated at $\sim 20 \mathrm{~K}$ with $1.5 \mathrm{MeV} \mathrm{Xe}^{+}$ions to a fluence of $5.0 \cdot 10^{15} \mathrm{Xe}$ $\mathrm{cm}^{-2}$. All of the grains in this sample retained their crystallinity for an ion dose which corresponds to about $5 \mathrm{dpa}$ at a depth of $50 \mathrm{~nm}$ in spinel and to about $8.5 \mathrm{dpa}$ in vanadium. However, the grain boundaries and the boundaries between vanadium and spinel did not exhibit similar resilience. All of the interfaces between particles appear to have been preferentially sputtered during the irradiation (see [19] for details).

Another TEM specimen from the same material was irradiated at room temperature

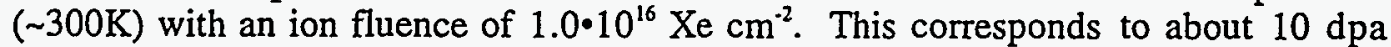
at a depth of $50 \mathrm{~nm}$ in spinel and to about $17 \mathrm{dpa}$ at a similar depth in vanadium. It was found that the microstructure of this vanadium-spinel composite is unaltered by the room temperature irradiation [19]. All of the crystalline grains before $\mathrm{Xe}^{+}$irradiation are still crystalline afterwards, while the glassy pockets remain amorphous following $\mathrm{Xe}^{+}$exposure. The interfaces between vanadium and spinel appear to resist alteration during irradiation, in contrast to the preferential sputtering phenomenon observed at interfaces during the $20 \mathrm{~K} \mathrm{Xe}^{+}$irradiation. The sizes of the microstructural features are approximately the same before and after irradiation and there is no evidence for the appearance of microvoids following irradiation. The only apparent changes in microstructure after irradiation are (i) a decrease in the contrast of the chevron-like twinned structure in large vanadium grains (Fig. 2); (ii) a diminished bend-contour contrast in spinel grains; and (iii) the appearance of mottled "blackspot" contrast in spinel grains. Though the glassy pockets appear unaltered by irradiation, they are undesirable from the perspective of optimized mechanical performance. In future vanadium-spinel synthesis experiments, efforts will be made to eliminate these amorphous inclusions, as well as to reduce the concentration of the impurities that segregate to grain boundaries. 


\section{Properties}

The average value of the CTE of composite VS- 1 between 50 and $475^{\circ} \mathrm{C}$ was determined to be $8.74 \cdot 10^{-6} \mathrm{~K}^{-1}$. This number compares well with the rule-of-mixtures prediction of $8.96 \cdot 10^{-6} \mathrm{~K}^{-1}$ derived from the published CTEs of vanadium and spinel [7,8] for the same temperature range. However, when the CTE data are plotted against temperature (Fig. 3) it is observed that the composite CTE initially follows the spinel line, but it approaches and crosses the vanadium CTE curve at higher temperatures. One possible explanation for this behavior is the dissolution of oxygen in vanadium, which can reach values exceeding 6 at.\% at $600^{\circ} \mathrm{C}$ [22]. This would cause an expansion in the vanadium lattice. Additional experiments under vacuum and at higher temperatures are planned to resolve this issue.

Hot hardness data obtained from the same composite, together with that from a pure vanadium and a hot-pressed spinel, are shown in Fig. 4. Vanadium is seen to behave like a typical pure metal which shows an Arrhenius-type temperature dependence for its hardness. The hardness of spinel, as expected, varies less with temperature and its value of $-7 \mathrm{GPa}$ at room temperature is somewhat lower than that reported in the literature $(\sim 14 \mathrm{GPa},[23])$. The hardness of the composite falls between the two. However, its room temperature hardness is about $5 \mathrm{GPa}$ which is much higher than that of various vanadium-base alloys ( $-2-3 \mathrm{GPa}$ at that temperature [21]). From this it can also be concluded that the high-temperature strength of the composite will be superior to that of vanadium-base alloys.

From the RUS measurements, the two independent elastic constants of the VS-1 composite were determined to be (in $\mathrm{GPa}$ ): $\mathrm{C}_{11}=302$ and $\mathrm{C}_{44}=84.3$. Other elastic constants: Young's modulus $=220 \mathrm{GPa}$, bulk modulus $=189 \mathrm{GPa}$, and Poisson's ratio $=0.306$. The elastic constants of composites VS-3, VS-4, and VS-5 were obtained by the pulse-echo method and the results are given in Table II, together with the rule-of-

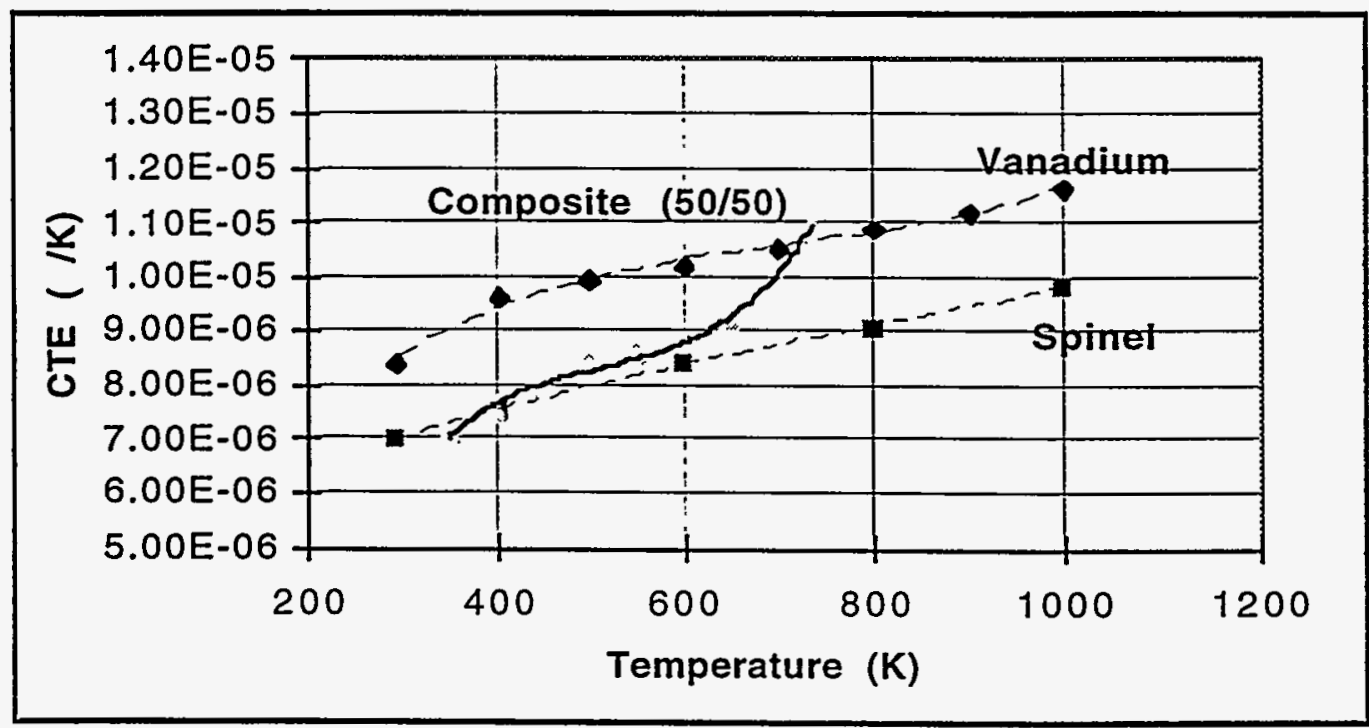

Figure 3. Variation of the CTE of composite VS-1 with temperature as compared to literature values of vanadium [7] and spinel $\left(\mathrm{MgO}^{2} \times \mathrm{Al}_{2} \mathrm{O}_{3}\right)[8]$. 


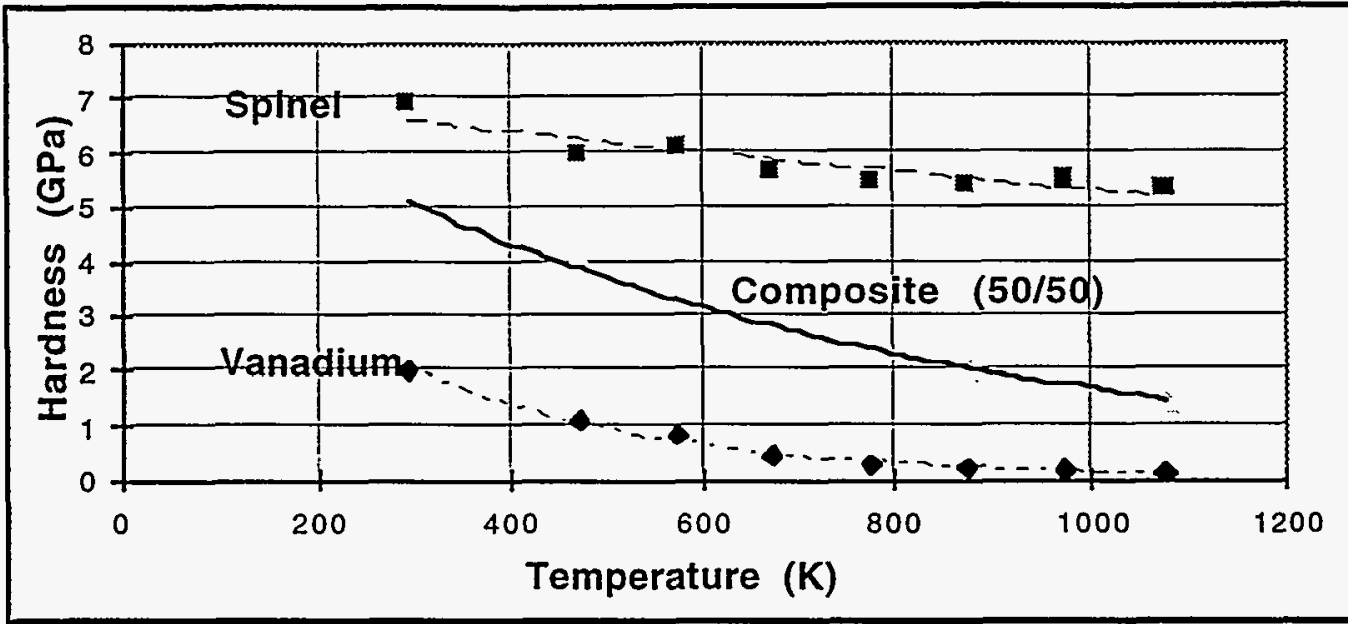

Figure 4. Vickers hardness vs. temperature. Loads, for vanadium and composite: $1000 \mathrm{~g}$; for spinel: $500 \mathrm{~g}$.

Table II. Mechanical Properties of Vanadium-Spinel Composites

\begin{tabular}{|c|c|c|c|c|c|}
\hline $\begin{array}{c}\text { Sample } \\
\text { ID }\end{array}$ & $\begin{array}{c}E_{\text {meas. }} \\
(\mathrm{GPa})\end{array}$ & $\begin{array}{c}\mathrm{E}_{\text {pred. }} \\
(\mathrm{GPa})\end{array}$ & $v_{\text {meas. }}$ & $v_{\text {pred. }}$ & $\begin{array}{c}\mathrm{K}_{\mathrm{Ic}} \\
\left(\mathrm{MPa} . \mathrm{m}^{1 / 2}\right)\end{array}$ \\
\hline VS-3 & 270 & 218 & 0.274 & 0.306 & 2.66 \\
\hline VS-4 & 245 & 203 & 0.283 & 0.315 & 3.08 \\
\hline VS-5 & 227 & 188 & 0.274 & 0.325 & 3.33 \\
\hline
\end{tabular}

mixtures predictions. The predictions are based on the following values from literature: vanadium, $\mathrm{E}=128 \mathrm{GPa}, \mathrm{v}=0.365$ [24]; spinel (stoichiometric, $\mathrm{MgAl}_{2} \mathrm{O}_{4}$ ), $\mathrm{E}$ $=278 \mathrm{GPa}, v=0.266[25]$. There is a relatively good match in the value of the Young's modulus for the two 50-50 composites (VS-1 and VS-4) considering the fact that they were obtained using different techniques. It is seen that all the Young's modulus predictions are underestimates. Although it is known that the modulus of spinel $\left(\mathrm{MgO} \times \mathrm{Al}_{2} \mathrm{O}_{3}\right)$ increases by up to $10 \%$ with $\times$ [26], the increase observed in our specimens is larger; however, the reason behind it is presently unknown.

The fracture toughness values shown in Table II are lower than expected, although they still represent significant improvements over the fracture toughness of monolithic spinel ( 1.4 MPa.m ${ }^{1 / 2}$, [2.7]). It should also be noted that the "maximum-load" version of the Chevron notch technique is known to provide a lower estimate of the fracture toughness compared to other methods (see [17] for details). It is clear, however, that the ductile phase toughening provided by vanadium is insufficient. Observations of the fracture surface provide clues about the reasons behind this behavior. We have seen that fracture mainly occurs at vanadium/vanadium and spinel/spinel interfaces, but rarely along vanadium/spinel interfaces. This observation indicates that the vanadium/spinel interfaces are strong as reported in other investigations of metalspinel composites [28]. As can be seen in Fig. 5, there is intergranular fracture in vanadium together with cleavage in large grains. Combined with the observation of 


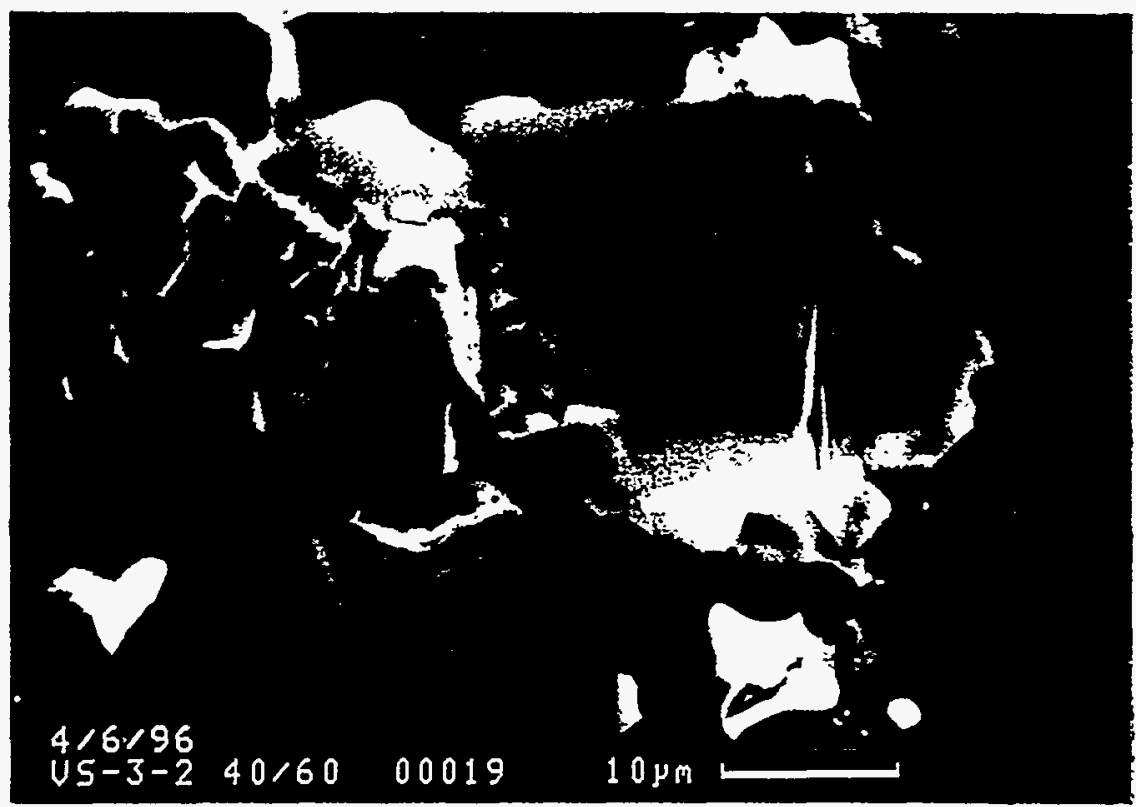

Figure 5. SEM image of the fracture surface of a specimen from composite VS-3 (40-60). The bright phase is vanadium.

twinning in vanadium (Fig. 2), this points to a relatively brittle behavior of vanadium. In other words, the DBTT of vanadium may have been raised to room temperature levels. In that case, the dominant deformation and fracture behavior of vanadium under ambient conditions would be twinning and cleavage [21]. It is well known that impurities such as $\mathrm{H}, \mathrm{O}, \mathrm{N}, \mathrm{B}$ and $\mathrm{C}$ can profoundly affect the mechanical properties of vanadium, even when they are present at several hundred ppm levels, and can significantly raise the DBTT [21]. Studies are underway to determine the amount of these impurities present in our composites.

Another interesting observation on fracture surfaces is indicated in Fig. 6. Here, in addition to intergranular fracture in the spinel phase, a small vanadium particle is seen to have "necked" and partially debonded along the vanadium/spinel interface. Such a behavior, if it had been more common, would have led to a ductile-phase toughening increase. Recent studies on metal-ceramic composites [29] suggest that maximum toughening by the metallic phase is realized when small $(\sim 1 \mu \mathrm{m}$ diameter) metal particles are distributed in a ceramic matrix with which they form a strong interface. This fact is supported by the observation in Fig. 6 . We have, therefore, ongoing efforts to produce vanadium-spinel composites with finer metal particles which employ mechanical alloying to decrease the initial metal particle size [30].

\section{CONCLUSION}

A new metal-ceramic composite has been developed consisting of a mixture of vanadium and magnesio-aluminate spinel. It has properties that make it an attractive structural material in hostile environments such as the first wall of a magnetic fusion reactor. In this paper, it was demonstrated that a 50-50 volume mixture vanadium- 


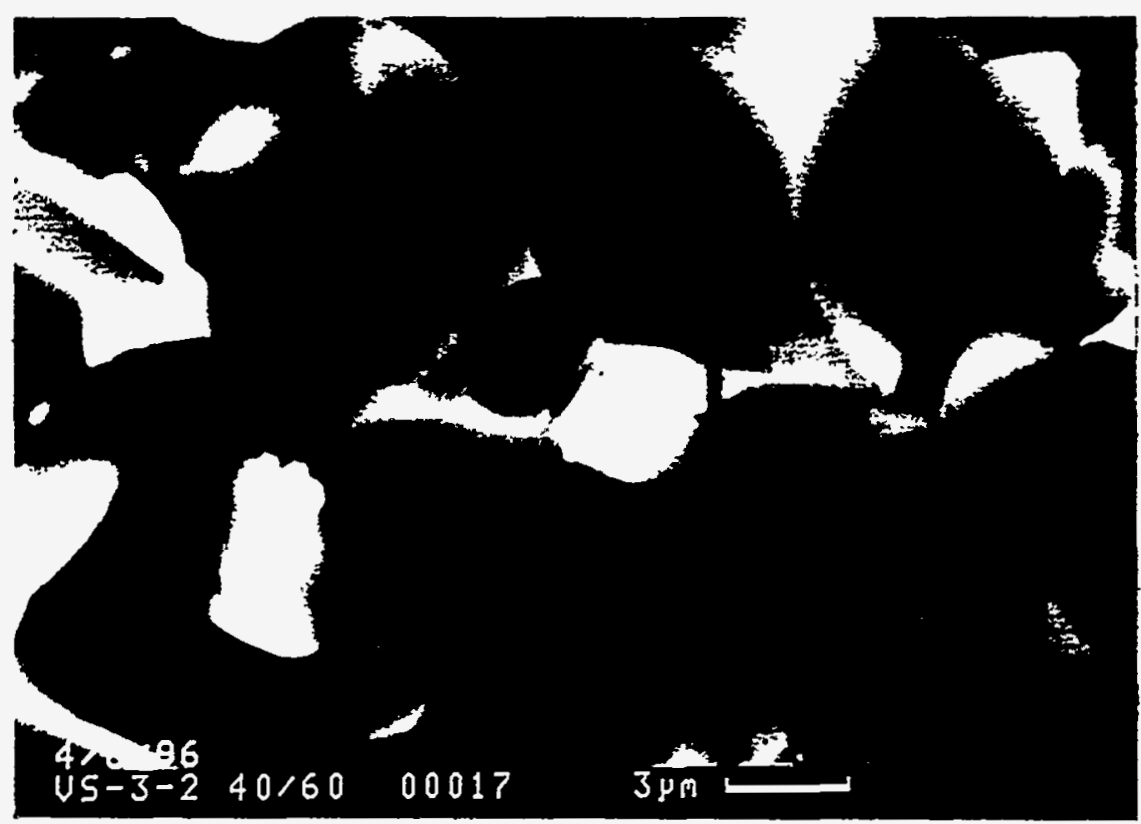

Figure 6. Fracture surface SEM image of a specimen cut from composite VS-3 (40-60). The bright phase is vanadium.

spinel hot-pressed composite sample experienced little or no microstructural evolution following a heavy ion (Xe) dose of between 10-17 dpa at room temperature. This result indicates that vanadium-spinel composites may possess high resistance to radiation-induced damage phenomena such as volume swelling. possibly due to some thermally-activated recovery mechanisms. The observed radiation resistance of vanadium-spinel composites was anticipated to some extent, based on the known radiation resistance properties of the constituents. $\mathrm{MgAl}_{2} \mathrm{O}_{4}$ single crystals have survived neutron exposures of up to $250 \mathrm{dpa}$ and exhibited virtually no change in physical dimensions or elastic properties [31]. Moreover, vanadium-base alloy's are distinguished for their swelling resistance, especially $\mathrm{V}-\mathrm{Cr}-\mathrm{Ti}$ alloys which have projected lifetimes for swelling $>250$ dpa [3]. If the radiation resistance of vanadium-spinel composites persists at the higher fusion first wall design temperatures $\left(-750^{\circ} \mathrm{C}\right)$, then vanadiumspinel structural composites may constitute attractive alternatives to the conventional first wall design materials. Vanadium-spinel composites are also attractive because of the high melting points of the constituents (which should enhance high temperature mechanical properties), the matching coefficients of thermal expansion of vanadium and spinel (which will increase the thermal shock/fatigue properties of the composite), their good thermal conductivity (based on the vanadium constituent), and the potential for high-toughness composites with strong interfaces. Our hot hardness measurements indicate that the composites have better high temperature strengths compared to vanadium-base alloys. Similarly, there was a significant improvement in the fracture toughness of the composite over that of monolithic spinel. However, the coarse vanadium microstructure and possibly the presence of impurities in it preclude the attainment of a higher fracture toughness. Our future studies will concentrate on microstructure control to enhance the mechanical properties of these composites. 


\section{ACKNOWLEDGMENTS}

We wish to thank S. L. Scott, V. A. Rosado, J. N. Mitchell, R. Devanathan, and K. Yasuda for sample preparation assistance and to E. D. Rodeghiero at Cornell University for executing the pulse-echo measurements. This study was sponsored by the US Department of Energy, Office of Basic Energy Sciences, Division of Materials Sciences and by a postdoctoral fellowship to E. Üstündag by Los Alamos National Laboratory.

\section{REFERENCES}

1. R. L. Klueh and P. J. Maziasz, in Reduced Activation Materials for Fusion Reactors, STP 1047, edited by R. L. Klueh, D. S. Gelles, M. Okada and N. H. Packan (American Society for Testing and Materials, Philadelphia, 1990), pp. 7-18.

2. D. S. Gelles, in Reduced Activation Materials for Fusion Reactors, STP 1047, edited by R. L. Klueh, D. S. Gelles, M. Okada and N. H. Packan (American Society for Testing and Materials, Philadelphia, 1990), pp. 113-129.

3. D. L. Smith, B. A. Loomis and D. R. Diercks, J. Nucl. Mater. 135 (1985) 125139.

4. S. Sharafat, R. H. Jones, A. Kohyama and P. Fenici, Fusion Engrg. Des. 29 (1995) 411-420.

5. T. B. Massalski, Ed., Binary Alloy Phase Diagrams, (American Society for Metals, 1986).

6. D. M. Roy, R. Roy and E. F. Osborn, J. Am. Ceram. Soc. 36 (5) (1953) 147-150.

7. Y. S. Touloukian, R. K. Kirby, R. E. Taylor and P. D. Desai, Thermal ExpansionMetallic Elements and Alloys, Thermophysical Properties of Matter, v. 12 (IFI/Plenum, New York, 1975), pp. 373-381.

8. Y. S. Touloukian, R. K. Kirby, R. E. Taylor and P. D. Desai, Thermal ExpansionNonmetallic Solids, Thermophysical Properties of Matter, v. 13 (IFI/Plenum, New York, 1977), pp. 479-482.

9. S. Majumdar, B. Misra and S. D. Harkness, in Fusion Reactor Design Concepts: Proceedings of a Technical Committee Meeting and Workshop, Madison, 10-21 October 1977 (International Atomic Energy Agency, Vienna, 1978), pp. 549560.

10. F.L. Yaggee, E.R. Gilbert and J.W. Styles, J. Less-Common Met. 19 (1969) 39-51.

11. W. D. Kingery, H. K. Bowen and D. R. UhImann, Introduction to Ceramics (John Wiley \& Sons, New York, 1976).

12. E. C. M. Pennings and W. Grellner, J. Am. Ceram. Soc. 72 (1989) 1268-1270.

13. A. Migliori, J. L. Sarrao, W. M. Visscher, T. Bell, M. Lei, Z. Fisk, and R. G. Leisure, Physica B 183 (1993) 1.

14. D. J. Babikov, Ultrasonics and Its Industrial Applications, (Consultants Bureau, New York, 1960). 
15. J. H. Underwood, S. W. Freiman and F. I. Baratta (eds.), Chevron-Notched Specimens: Testing and Stress Analysis, ASTM STP 855, (American Society for Testing and Materials, Philadelphia, 1984).

16. Wu Shang-Xian, in Chevron-Notched Specimens: Testing and Stress Analysis, ASTM STP 855, J. H. Underwood et al. (eds.), (American Society for Testing and Materials, Philadelphia, 1984), pp. 176-192.

17. E. Üstündag, E. D. Rodeghiero, H. J. Yoo and A. T. Zehnder, to be submitted to Acta Mater. (1996).

18. C. W. Allen, L. L. Funk, E. A. Ryan and S. T. Ockers, Nucl. Instr. and Meth. B 40/41 (1989) 553.

19. K. E. Sickafus, R. Raj and P. C. Panda, submitted to J. Nucl. Mater. (1996).

20. J. F. Ziegler, J. P. Biersack and U. Littmark, The Stopping and Range of Ions in Solids (Pergamon Press, New York, 1985).

21. D. L. Harrod and R. E. Gold, Inter. Met. Rev. 25[4] (1980) 163-221.

22. C. B. Alcock and C. Ji, High Temp.-High Pressures, 22 (2) (1990) 139-147.

23. I. J. McColm, Ceramic Hardness, (Plenum Press, New York, 1990), p. 282.

24. H. E. Boyer and T. L. Gall (eds.), Metals Handbook, Desk Ed., (American Society for Metals, Metals Park, OH, 1985).

25. Engineered Materials Handbook, v. 4, Ceramics and Glasses, (American Society for Metals, Metals Park, OH, 1991).

26. G. Simmons and H. Wang, Single Crystal Elastic Constants and Calculated Aggregate Properties: A. Handbook, $2^{\text {nd }}$ ed., (MIT Press, Cambridge, MA, 1971), pp. 277-278.

27. R. W. Rice, S. W. Freiman and J. J. Mecholsky, J. Am. Ceram. Soc. 63 (3-4) (1980) $129-136$.

28. T. W. Gustafson, P. Panda, G. Song and R. Raj, submitted to Mater. Sci. Eng. A (1995).

29. R. Raj and 1. R. Thompson, Acta Metall. 42 (12) (1994) 4135-4142.

30. E. Üstündag, T. D. Shen, K. E. Sickafus and R. B. Schwarz, work in progress (1996).

31. F. A. Garner, G. W. Hollenberg, F. D. Hobbs, J. L. Ryan, Z. Li, C. A. Black and R. C. Bradt, J. Nucl. Mater. 212-215 (1994) 1087. 